Archived version from NCDOCKS Institutional Repository http://libres.uncg.edu/ir/asu/

\title{
Appalachlyan
}

B O O N E, NORT H C A R O L I A

\section{Substance P In The Uterine Cervix, Dorsal Root Ganglia And Spinal Cord During Pregnancy And The Effect Of Estrogen On SP Synthesis}

\author{
Authors \\ C.N. Mowa, S.Usip, M. Storey-Workley, R. Amann, R. Papka
}

\begin{abstract}
Prior to parturition the non-pliable uterine cervix undergoes a ripening process ("softens" and dilates) to allow a timely passage of the fetus at term. The exact mechanism(s) triggering and involved in cervical ripening are unknown, though evidence for a role for sensory neurons and their contained neuropeptides is emerging. Moreover, an apparent increase in neuropeptide immunoreactive nerves occurs in the cervix during pregnancy, maternal serum estrogen levels rise at term and uterine cervix-related L6-S1 dorsal root ganglia (DRG) sensory neurons express estrogen receptor (ER) and neuropeptides. Thus, we sought to test the hypothesis that the neuropeptide substance P (SP) changes biosynthesis and release over pregnancy, that estrogen, acting via the ER pathway, increases synthesis of SP in DRG, and that SP is utilized in cervical ripening at late pregnancy. Using immunohistochemistry, in situ hybridization, reverse transcriptase-polymerase chain reaction (RT-PCR) and radioimmunoassay (RIA), we investigated coexpression of ER-G/13 and SP; differential expression of ER-G and -13 mRNA in DRG neurons; SP synthesis in DRG; and changes in SP concentration in the cervix, DRG and spinal cord over pregnancy. In addition, the effect of exogenous estrogen on SP synthesis in L6-S1 DRG of ovariectomized rats was examined. SP-immunoreactive neurons expressed ER-G and ER-13. SP synthesis (expressed as 13-PPT mRNA label) was prominent in small DRG neurons. SP concentration increased in the L6-S1 DRG and spinal cord segments, with a peak at Day 20 of gestation, but decreased in the cervix during the first two trimesters, with a rise over the last trimester to Day 10 levels. SP and ER-G mRNA synthesis increased in DRG over pregnancy but ER-13 mRNA levels were largely unchanged. When ovariectomized rats were treated with exogenous estrogen, SP mRNA synthesis in the DRG increased in a dose-related manner, an effect blocked by ER blocker ICI 182 780. From these results, we postulate that synthesis of SP in L6-S1 DRG and utilization in the cervix increase over pregnancy and this synthesis is under influence of the estrogen-ER system, most likely ER-G. We postulate that SP may play a role in cervical ripening and, consequently in the birth process.
\end{abstract}

C.N. Mowa, S.Usip, M. Storey-Workley, R. Amann, R. Papka (2003) "Substance P In The Uterine Cervix, Dorsal Root Ganglia And Spinal Cord During Pregnancy And The Effect Of Estrogen On SP Synthesis" Peptides volume 24 pg. 761-771 [DOI:10.1016/S0196-9781(03)00120-7] Version of Record Available @ www.sciencedirect.com 


\title{
Substance $\mathrm{P}$ in the uterine cervix, dorsal root ganglia and spinal cord during pregnancy and the effect of estrogen on SP synthesis
}

\author{
C.N. Mowa ${ }^{\text {a }}$, S. Usip ${ }^{\text {a }}$, M. Storey-Workley ${ }^{\mathrm{a}}$, R. Amann ${ }^{\mathrm{b}}$, R. Papka ${ }^{\mathrm{a}}{ }^{\mathrm{a}}$ \\ ${ }^{a}$ Department of Neurobiology and Pharmacology, Northeastern Ohio Universities College of Medicine, \\ P.O. Box 95, 4209 State Rt. 44, Rootstown, OH 44272, USA \\ ${ }^{\mathrm{b}}$ Department of Experimental and Clinical Pharmacology, University of Graz, Graz, Austria
}

\begin{abstract}
Prior to parturition the non-pliable uterine cervix undergoes a ripening process ("softens" and dilates) to allow a timely passage of the fetus at term. The exact mechanism(s) triggering and involved in cervical ripening are unknown, though evidence for a role for sensory neurons and their contained neuropeptides is emerging. Moreover, an apparent increase in neuropeptide immunoreactive nerves occurs in the cervix during pregnancy, maternal serum estrogen levels rise at term and uterine cervix-related L6-S1 dorsal root ganglia (DRG) sensory neurons express estrogen receptor (ER) and neuropeptides. Thus, we sought to test the hypothesis that the neuropeptide substance P (SP) changes biosynthesis and release over pregnancy, that estrogen, acting via the ER pathway, increases synthesis of SP in DRG, and that SP is utilized in cervical ripening at late pregnancy. Using immunohistochemistry, in situ hybridization, reverse transcriptase-polymerase chain reaction (RT-PCR) and radioimmunoassay (RIA), we investigated coexpression of ER-G/13 and SP; differential expression of ER-G and -13 mRNA in DRG neurons; SP synthesis in DRG; and changes in SP concentration in the cervix, DRG and spinal cord over pregnancy. In addition, the effect of exogenous estrogen on SP synthesis in L6-S1 DRG of ovariectomized rats was examined. SP-immunoreactive neurons expressed ER-G and ER-13. SP synthesis (expressed as 13-PPT mRNA label) was prominent in small DRG neurons. SP concentration increased in the L6-S1 DRG and spinal cord segments, with a peak at Day 20 of gestation, but decreased in the cervix during the first two trimesters, with a rise over the last trimester to Day 10 levels. SP and ER-G mRNA synthesis increased in DRG over pregnancy but ER-13 mRNA levels were largely unchanged. When ovariectomized rats were treated with exogenous estrogen, SP mRNA synthesis in the DRG increased in a dose-related manner, an effect blocked by ER blocker ICI 182 780. From these results, we postulate that synthesis of SP in L6-S1 DRG and utilization in the cervix increase over pregnancy and this synthesis is under influence of the estrogen-ER system, most likely ER-G. We postulate that SP may play a role in cervical ripening and, consequently in the birth process.
\end{abstract}

Keywords: Parturition; Estrogen; Estrogen receptor; Sensory neurons; Neurogenic inflammation; Pregnant rat

\section{Introduction}

During pregnancy the quiescent uterus provides a favorable environment for the growing fetus and the non-pliable cervix acts as a sphincter to keep the fetus in utero. However, at term the cervix undergoes tissue remodeling leading to softening and dilatation ('ripens'), whereas the uterus contracts to facilitate passage of the fetus. Failure of either or both of these events leads to birthing problems such as preterm birth or protracted labor [13].

Cervical ripening is a complex process that is regulated by numerous factors, many of which have been studied extensively such as nitric oxide, cytokines, prostaglandins, relaxin and steroids hormones $[1,18,51,83]$. However, the exact mechanism(s) triggering cervical ripening remain elusive. Moreover, changes in the cervix at ripening are similar to those seen in inflammatory reactions, especially neurogenic inflammation [16,42], suggesting that nerves play an important role in cervical ripening. However, even though it is known that the cervix is richly innervated with autonomic and sensory nerves $[4,57-59,85]$ and that transection of the sensory nerves blocks labor [10,27], the role of uterine cervix-related nerves is poorly understood.

Our laboratory has established the fundamental anatomic organization essential for neurogenic inflammation in the cervix of parturient rats, which we believe may play a crucial role in cervical ripening [16]. Uterine cervical afferent nerves, containing inflammation-associated neuropeptides, including substance $\mathrm{P}(\mathrm{SP})$, are closely associated with leaky 
venules and smooth muscle cells in the cervix of parturient rats [16]. Interestingly, administration of SP to ovariectomized rats mimics aspects of neurogenic inflammation observed in the parturient cervix, i.e. immune cell recruitment, vasodilation and plasma extravasation, suggesting that SP may play an important role in cervical ripening [16].

$\mathrm{SP}$ is a member of the tachykinin family of peptide neurotransmitters, namely SP, neurokinin A (NKA) and neurokinin $\mathrm{B}(\mathrm{NKB})$, that are derived from preprotachykinin (PPT) gene by alternative splicing [12,53]. Moreover, three distinct $\mathrm{G}$ protein-coupled cell membrane receptors, NK1, 2 and 3, are activated preferentially by SP, NKA and NKB, respectively $[49,70]$. SP is found in sensory nerves innervating peripheral tissues $[28,55,71,72]$ including the uterine cervix $[16,57,59,79]$ and, when locally released, causes pain and neurogenic inflammation $[21,29]$. In addition, NK1 receptor immunoreactivity is associated with target tissues in the cervix and its synthesis increases over pregnancy [16]. However, to date studies are not available on the effects of changing estrogen levels in the cervix over pregnancy, its influence on neurotransmitters and their potential involvement in cervical ripening.

Several studies have established that (i) maternal serum estrogen levels rise over pregnancy peaking near term $[8,46,76]$, (ii) dorsal root ganglion (DRG) neurons express estrogen receptor (ER) $[63,64,82]$ including those in the L6-S1 segmental DRG that innervate the uterus $[60,65,67]$, (iii) some ER containing DRG neurons express SP $[60,61]$, and (iii) SP is transported to the pelvic organs (cervix included) from L6-S1 DRG $[48,67]$. On the basis of these data, we hypothesize that rising estrogen levels at term could stimulate, via ER, an increased synthesis of SP. The neuropeptide is then transported to sensory nerve terminals in the cervix for release and binding to NK1 receptors to participate in remodeling of the cervix.

To test this hypothesis, the present study utilized immunohistochemistry, in situ hybridization, RT-PCR and radioimmunoassay (RIA) to investigate coexpression of ER and SP in DRG neurons, SP synthesis in DRG, and changes in SP concentration in the cervix, DRG and spinal cord over pregnancy. The effect of exogenous estrogen on SP synthesis was investigated in ovariectomized rats.

\section{Materials and methods}

\subsection{Animals}

Adult female Sprague-Dawley rats (SASCO strain from Charles Rivers) were used in these studies. Nonpregnant and timed-pregnant rat at gestational days 10, 15, 20, parturient (Day 22) and 2-day postpartum were included in the studies.

A total number of 90 pregnant animals $[n=5$ (radioimmunoassay, immunohistochemistry and in situ hybridization) and $n=3$ (RT-PCR) representative time points] and 18 nonpregnant animals $[n=3$ for each type of treatment (1713-estradiol and ER blocker, ICI 182 780) were used]. All experiments were performed in accordance with the NIH Guide for the Care and Use of Laboratory Animals (NIH Publications No. 86-23) revised 1985. During all experiments efforts were made to minimize both animal suffering and numbers of animals used.

\subsection{Radioimmunoassay}

Pregnant rats were euthanized with sodium pentobarbital ( $100 \mathrm{mg} / \mathrm{kg}$ body weight, i.p.), and perfused intra-cardially only with $0.9 \%$ sodium chloride. The cervix, L6-S1 DRG and spinal cord segments (dorsal one-half only) were carefully removed and stored frozen at $-80{ }^{\circ} \mathrm{C}$ until processing. Frozen samples were homogenized and extracted in $2 \mathrm{~N}$ acetic acid. An aliquot of the homogenate was used for protein determination (Bio-Rad). After centrifugation, the supernatants were lyophilized and used for RIA. SP was determined using antiserum RD2 (gift of Dr. S.E. Leeman), $\left[{ }^{125} \mathrm{I}\right]$ Bolton-Hunter-SP (Amersham) as radioligand and synthetic SP (Sigma Chemical Co., St. Louis, MO) as standard [40].

\subsection{Immunohistochemistry}

For immunohistochemical studies of the expression of ER and SP in DRG neurons, nonpregnant rats were ovariectomized. Animals were anesthetized with sodium pentobarbital $(45 \mathrm{mg} / \mathrm{kg}$, i.p.) and ovariectomized via two small dorsal incisions. Incisions were closed with a single stitch to the muscle layer and a single wound clip to the skin. After 7-10 days survival the rats were deeply anesthetized $(100 \mathrm{mg} / \mathrm{kg}$ sodium pentobarbital, i.p.) and exsanguinated by cardiac perfusion with saline followed by $4 \%$ para-formaldehyde in $0.1 \mathrm{M}$ phosphate buffer, $\mathrm{pH} 7.3$. The L6-S1 DRG were removed, cryoprotected in 30\% sucrose, frozen, and sectioned (14 $\mu \mathrm{m}$ thick) on a cryostat. Sections were processed on slide for immunohistochemistry to localize SP and ER-G or ER-13 by standard techniques routinely used in our laboratory [58,60-63]. Briefly, sections of DRG were incubated for $16-24 \mathrm{~h}$ at room temperature with a cocktail of primary antibodies: (i) a guinea pig generated antibody against SP (dilution 1:800; gift of Dr. Catia Sternini, CURE at UCLA, Los Angeles, CA) and a rabbit generated antibody against ER-G (1:2500 dilution; code 1355; gift of Dr. Margaret Shupnik, University of Virginia and same antibody purchased from Upstate Biotechnology) or (ii) the SP antibody plus a sheep generated anti-ER-13 antiserum (1:5000 dilution; code 893/3/34; 41/P3; gift of Dr. Phillipa T.K. Saunders, MRC Human Reproductive Sciences, Edinburgh, UK). Sections were washed in phosphate buffered saline (PBS), incubated in a mixture of appropriate secondary antibodies: donkey anti-guinea pig $\operatorname{IgG}$ labeled with CY-3 (1:800 dilution) (Jackson Immunoresearch) + donkey anti-rabbit IgG labeled with Alexa 488 (Molecular Probes) or donkey anti-guinea pig IgG labeled with CY-3 (Jackson 
Immunoresearch) + donkey anti-sheep IgG labeled with Alexa 488 (1:100 dilution) (Molecular Probes) for $1 \mathrm{~h}$ and mounted in PBS:glycerol.

The SP antibody is well characterized [59]. The ER-G antiserum coded $\mathrm{C} 1355$ was raised against the last 14 amino acids of the ER and its characterization is established [24]. The ER-13 antiserum was raised in sheep against the N-terminal (code 893/3/34 and 41/P3) and the hinge (code 913/1/36/P4) regions of the ER protein [75]. Controls included omission of the primary antiserum, omission of the secondary antibody, absorption of the primary antiserum with its respective antigen $(10 \mu \mathrm{g} / \mathrm{ml}$ of diluted antiserum), and cross-absorption controls.

Tissue sections were viewed with an Olympus Provis Microscope equipped for epifluorescence microscopy (single excitation and emission and dual excitation/emission filters for Alexa488/FITC and CY-3/TRITC). Images were captured with a SPOT ${ }^{\mathrm{TM}}$ Digital Camera (Diagnostics Instruments, Sterling Heights, MI), imported into PhotoShop ${ }^{\mathrm{TM}}$ V 5.5 (Adobe Systems Inc., San Jose, CA), contrast and brightness adjusted if necessary, labeled and then printed.

In sections immunostained for ER-G + SP and ER-13 + SP neuron somal profiles were estimated (percentage) to present an idea of relative frequency of subpopulations expressing subtypes of ER and the neuropeptide. Nonadjacent, doublestained sections of L6 and S1 DRG from each of three rats $(n=3)$ were mounted on separate slides. From each rat nine randomly chosen fields were photographed using a $20 \times$ objective and then printed. The number of ER-positive, SP-positive, ER + SP-positive and negative somal profiles in each field were counted from prints and the percentage and standard error were calculated. Only somal profiles with a distinct ER-labeled nucleus or distinct SP-labeled cytoplasm were counted as positive and only profiles with a distinctively unlabeled nucleus or cytoplasm were counted as negative. Profiles in which neither a distinctly labeled nor unlabeled nucleus could be identified, i.e. a profile sectioned through cytoplasm, were omitted from counts.

\subsection{In situ hybridization (ISH)}

In situ hybridization was employed to identify the neurons synthesizing 13-PPT mRNA (and therefore expressing $\mathrm{SP}$ ) in the L6-S1 DRG during pregnancy and at postpartum. Pregnant animals were euthanized with sodium pentobarbital (100 mg/kg body weight, i.p.) and perfused intra-cardially only with $0.9 \%$ sodium chloride. The L6-S1 DRG were then carefully removed and stored frozen at $-80{ }^{\circ} \mathrm{C}$ until processing.

\subsubsection{Preparation of probes}

ISH used specific riboprobes. The 13-PPT mRNA plasmid constructs were generated and kindly supplied by Dr. James E. Krause (Neurogen Corp., Bradford, CT). cDNA fragment of 13-PPT was cloned into the multiple cloning site of pG1 (Stratagene\# 212205) using restriction enzymes.
The plasmid was linearized with EcoRI and BamHI restriction enzymes, which cut specifically in the polylinker region at the opposite end of the insert from the RNA polymerase promotor that transcribes the cRNA. It was then purified, washed, and concentrated at $200 \mathrm{ng} / \mathrm{ml}$ in $1 \times \mathrm{TE}$. Antisense and sense cRNA probes were synthesized using ${ }^{35}$ S-UTP (New England Nuclear), purified over a nick column (Pharmacia Biotech, USA) and evaluated on a Bio-Rad $5 \%$-urea ready gel to confirm size of probe and length. Only probes showing a single band in each lane were used for the experiment. Those showing a ladder pattern in each lane were discarded.

\subsubsection{Tissue processing and hybridization}

Cryostat sections mounted on slides were fixed in $4 \%$ para-formaldehyde ( $\mathrm{pH} 9.0)$, acetylated with $0.25 \%$ acetic anhydride in 0.1 triethanolamine (TEA; pH 8.0), washed in $2 \times \mathrm{SSC}$, dehydrated in ethanol series and air-dried before hybridization. Hybridization was performed at $55^{\circ} \mathrm{C}$ for $15-18 \mathrm{~h}$. The slides were then washed in the following post-hybridization buffers: thrice $2 \times \mathrm{SSC}$ (with DTT), treated with RNase A, washed in $1 \times \mathrm{SSC}$ at room temperature $(\mathrm{RT})$, washed thrice in $0.1 \times \mathrm{SSC}$ between 63 and $67^{\circ} \mathrm{C}$ and dehydrated in ethanol series. The slides were then air-dried and apposed to hyperfilm-13 max, prior to dipping them in Kodak NTB2 nuclear emulsion and exposure.

\subsection{Estrogen treatment}

In order to determine whether estrogen regulates SP synthesis via the classical ER pathway nonpregnant rats were ovariectomized as described above. After 2 weeks, the rats were treated with either increasing doses of 1713-estradiol (Sigma Chemical Co.) $(0.03,0.3,3.0,30.0 \mu \mathrm{g}$ per rat daily for 4 days, s.c., sacrificed $12 \mathrm{~h}$ after last injection) or ER antagonist ICI 182780 (AstraZeneca, Cheshire, UK) (s.c., $4 \mathrm{mg} / \mathrm{kg}$ once $12 \mathrm{~h}$ prior to $0.3 \mu \mathrm{g} 1713$-estradiol, sacri- ficed $12 \mathrm{~h}$ later) dissolved in $100 \mu \mathrm{l}$ of sesame oil. Other ovariectomized animals were treated only with vehicle (100 $\mu \mathrm{l})$.

\subsection{Total RNA isolation}

Animals (pregnant and ovariectomized rats) were euthanized with sodium pentobarbital (100 mg/kg body weight), IP, and perfused only with $0.9 \%$ sodium chloride. The L6-S1 DRG were then carefully removed and stored in the $-80{ }^{\circ} \mathrm{C}$ freezer until processing. Total RNA was isolated from L6-S1 DRG of individual animals using RNeasy Mini Kit (Qiagen, Valencia, CA). The amount and purity of total RNA for each sample were estimated by spectrophotometric analysis at A260 and A280. The quality of RNA was determined by agarose gel electrophoresis following ethidium bromide staining. Aliquots of total RNA were diluted in diethylpyrocarbonated (DEPC)-treated water and stored at $-80^{\circ} \mathrm{C}$. 


\subsection{Semi-quantitative reverse transcription-polymerase chain reaction $(R T-P C R)$}

Total RNA from DRG and spinal cord was reverse transcribed and amplified in an eppendorf Master Cycler, using reagents from Gene AMP Gold RNA PCR Kit (P.E. Biosystems, Foster City, CA), according to manufacturer's instructions. Briefly, 0.5-1 $\mu \mathrm{g}$ total RNA was reverse transcribed and amplified in a $50 \mu \mathrm{l}$ reaction mixture containing the following: $5 \times \mathrm{RT}-\mathrm{PCR}$ buffer, $1.75 \mathrm{mM} \mathrm{MgCl}$, $1.2 \mathrm{mM}$ dNTP's, $10 \mathrm{U}$ RNase inhibitor, $5.0 \mathrm{mM}$ DTT, $1 \mu \mathrm{M}$ random hexamer, $200 \mathrm{nM}$ SP, ER-G or ER-13 (for-

pliTaq Gold DNA polymerase, $30 \mathrm{U}$ MultiScribe reverse

tocol used for SP (modification of [41]) was as follows: pre-heated for $10 \mathrm{~min}$ at $94{ }^{\circ} \mathrm{C}$ followed by $1 \mathrm{~min}$ at $94{ }^{\circ} \mathrm{C}$, $1 \mathrm{~min}$ at $60^{\circ} \mathrm{C}, 2 \mathrm{~min}$ at $72^{\circ} \mathrm{C}$ for 29 cycles and finally $10 \mathrm{~min}$ at $72^{\circ} \mathrm{C}$. The RT-PCR protocol used for ER-G and -13 has been described earlier [82]. The sequences used for SP, ER-G and ER-13 were as follows: (i) SPforward: $5^{1}$-ATG-AAA-ATC-CTC-GTG-GCG-GT- $3^{1}$, reverse: $5^{1}$-CAG-CAT-CCC-GTT-TGC-CCA-TT-3 ${ }^{1}$ (217-bp fragment); (ii) ER-G-forward: $5^{1}$-TCC-TTC-TAG-ACCCTT-CAG-TGA-AGC-C- $3^{1}$, reverse: $5^{1}$-ACA-TGT-CAAAGA-TCT-CCA-CCA-TGC-C-3 ${ }^{1}$ (287-bp fragment); (iii) ER-13 - forward: $\quad 5^{1}$-CTC-GGG-GTC-TGA-GTG-CAG-CTC-AAC-3 ${ }^{1}$, reverse: $5^{1}$-CCG-AGA-GCC-TTC-AAG-GCTATA-CAA-G- $3^{1}$ (285-bp fragment).

The RT-PCR reactions were normalized across runs using $18 \mathrm{~S}$ ribosomal RNA as a standard. A Quantum RNA Kit with $18 \mathrm{~S}$ primers and competimers for quantitative RT-PCR was used (Ambion, Austin, TX). The ribosomal primers for this kit yielded a 488-bp PCR fragment. The PCR product was separated using agarose gel electrophoresis, visualized after staining with SYBR Green 1 and scanned using the Kodak 1D Image Station (Rochester, NY).

\subsection{Statistical analysis}

RIA and RT-PCR data are shown as means and S.D. (Figs. 1 and 4). Comparisons among groups were made by ANOVA and $t$-test. $P$ values less than 0.05 were considered significant.

\section{Results}

\subsection{Radioimmunoassay}

3.1.1. SP levels change in the cervix, DRG and spinal cord over the course of pregnancy

RIA analysis revealed increasing SP concentrations in the L6-S1 DRG and spinal cord segments over pregnancy with a peak at about Day 20 of gestation and nearly a three-fold increase in SP concentration between Days 10 and 20 of

\section{A. Dorsal root ganglion (L-S1)}

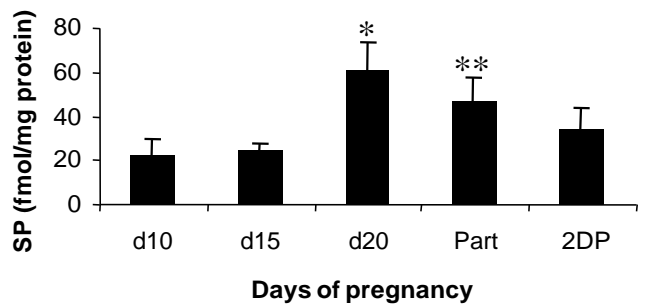

\section{B. Spinal cord}
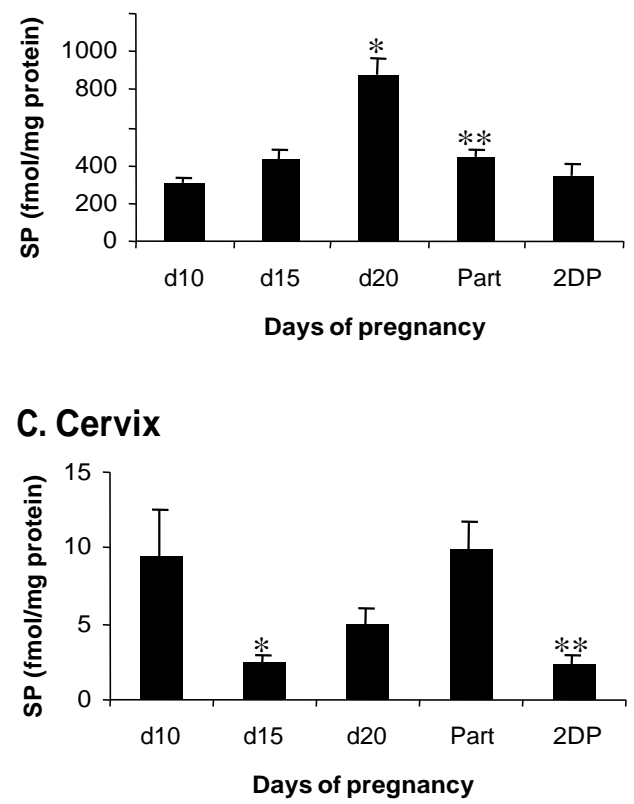

Fig. 1. Substance P (SP) concentration in the L6-S1 DRG (A), L6-S1 spinal cord (B) and uterine cervix (C) of pregnant and postpartum rats as revealed by radioimmunoassay (RIA). In the DRG (A) and spinal cord (B), SP concentration increases during pregnancy with a peak at about Day 20, and then decreases thereafter. In the cervix (C), SP concentration shows a decrease over pregnancy with a slight increase at about Days 15-20, but increases at parturition. Values are the mean and SE of SP concentration $(n=5)$. DRG: ${ }^{* *} P<0.0072,{ }^{*} P<0.0671$, compared to Day 10; spinal cord: ${ }^{*} P<0.0001,{ }^{*} * P<0.0001$, compared to Day 10 ; cervix, ${ }^{*} P<0.0091$, ${ }^{* *} P<0.01$, compared to Day 10 , (Dunnet's $t$-test).

pregnancy $(P<0.0072)$ (Fig. $1 \mathrm{~A}$ and $\mathrm{B})$. The SP concentration in the cervix showed a trend of decreasing between Days 10 and 15 of pregnancy and then a rise thereafter over the last trimester of pregnancy when it returns to Day 10 levels (Fig. 1C).

\subsection{Immunohistochemistry}

\subsubsection{Sensory neurons of DRG coexpress $S P$ and ERs}

Sections of L6-S1 DRG immunostained for ER-G or ER13 indicate a subpopulation of neurons immunoreactive for each receptor subtype as well as both ERs (see [62]). The focus of this study is on neurons that express ER as 
well as SP immunoreactivity. Sections double immunostained with a cocktail of antibodies against ER-G + SP and ER-13 + SP revealed subpopulations of neurons immunoreactive for ER-G, ER-13, SP, ER-G + SP, and ER-13 + SP
(Fig. 2). About $6.4 \%$ of somal profiles estimated were immunoreactive for both ER-G + SP and about $15.1 \%$ for ER-13+SP. Though triple immunostaining ganglion sections was not attempted, one should consider, based on previous
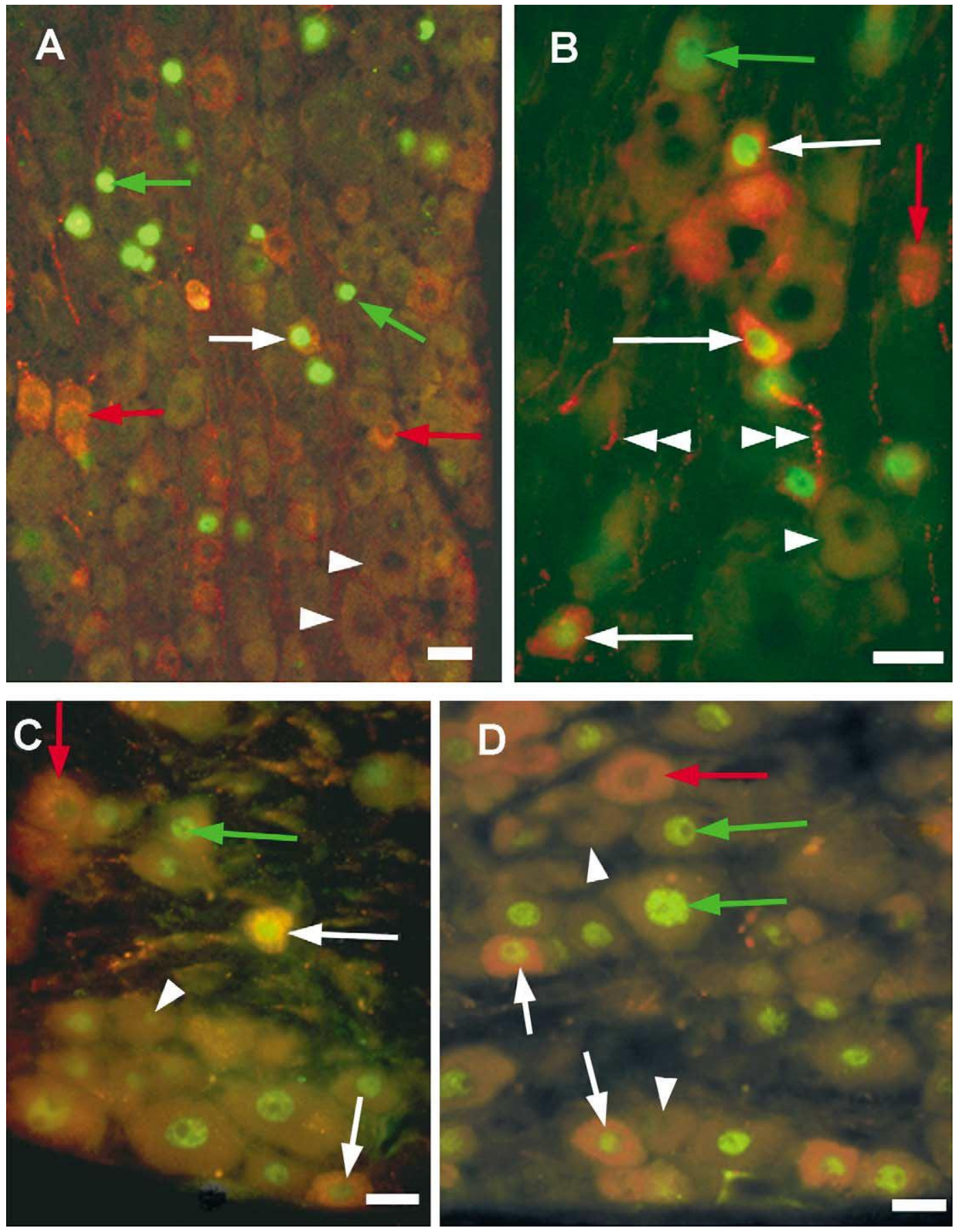

Fig. 2. Cryostat sections of the L6-S1 dorsal root ganglia (DRG) from ovariectomized rats double immunostained for ER-G + SP $(A, B)$ and ER-13 + SP (C, D). Low magnification view (A) and higher magnification view (B) of the DRG. The nuclei of some DRG neurons are stained only for ER-G (green arrows, green nuclei in A, B) and some for ER-13 (green arrows, green nuclei in C, D). Other DRG somata express only SP immunoreactivity (red arrows and red cytoplasm in A-D). Some neurons are double stained for ER-G + SP (white arrows, green nuclei + red cytoplasm in A, B) and some are double stained for ER-13 + SP (white arrows, green nuclei + red cytoplasm in C, D). White arrowheads in A-D indicate neurons that do not express SP nor ER. Double arrowheads in B indicate SP-immunoreactive processes coursing in the ganglia. A specific geographical concentration of subtypes of neurons within the DRG was not evident. Scale bar $=25 \mu \mathrm{m}$ for all figures. 


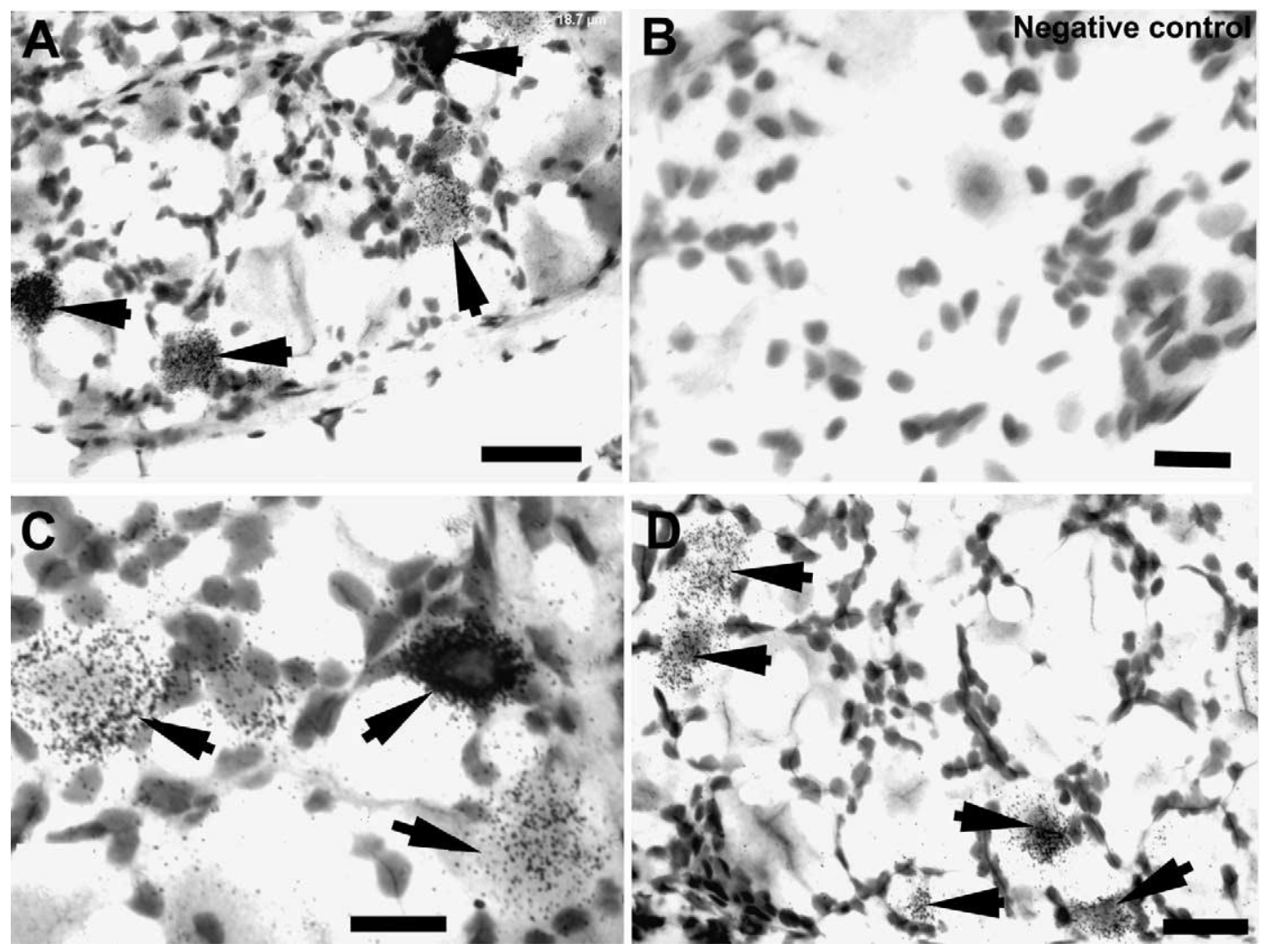

Fig. 3. In situ hybridization analysis showing expression of SP gene as 13-PPT mRNA hybridization signal (silver grains) in neurons of rat L6-S1 DRG at representative time points during pregnancy (Day 20: A, B, C) and at 2-day postpartum (D). Distinct signals (silver grains) localize largely to small (arrowhead) neurons in pregnancy and 2-day postpartum (A, C, D). Overall, the signal intensity in Day 20 pregnant animals was greater than in 2-day postpartum rats (comparable areas shown in C and D). B is a control section hybridized with the sense probe and shows lack of labeling. Scale bar $=20 \mu \mathrm{m}$ for all figures.

data [62] that some neurons may express both ER-G + ER-13+SP.

\subsection{In situ hybridization}

\subsubsection{Sensory neurons of DRG express $\beta$-PPT $m R N A$ and synthesize SP}

In order to confirm a subpopulation of neurons synthesizing and expressing SP in the L6-S1 DRG during pregnancy and at postpartum, ISH for 13-PPT mRNA was performed. 13-PPT mRNA signals were localized in small and medium size neurons of L6-S1 DRG throughout the stages of pregnancy examined (Days 10, 15, 20, parturition) and 2-day postpartum (Fig. 3).

\section{4. $R T-P C R$}

\subsubsection{SP mRNA in L6-S1 DRG is up-regulated over} Days 10, 15, 20, parturient (Day 22) of pregnancy and down-regulated by 2-day postpartum

SP mRNA bands showed a noticeable density increase over pregnancy and an apparent decrease by 2 -days postpartum (Fig. 4A). This change became more apparent when the bands were scanned using the Kodak 1D Image Sta- tion to produce a histogram of the net intensity of the bands (Fig. 4A, right). The difference in net intensity of bands at parturient (Day 22) versus Day 10 was statistically significant $(P<0.05)$.

\subsubsection{Exogenous estrogen up-regulates SP mRNA in L6-S1} $D R G$ and this effect can be blocked by ER antagonist ICI 182780

Ovariectomized rats treated with increasing doses of 1713 -estradiol $(0.03,0.3,3$, and $30 \mu \mathrm{g}$ per rat per day for 4 days) showed a dose-related increase of SP mRNA synthesis in L6-S1 DRG between the ranges of 0.03-3.0 $\mu \mathrm{g}$ (no further response was observed beyond $3.0 \mu \mathrm{g}$ ) (Fig. 4B). There was a statistical difference between dosages 0.03 and $0.3 \mu \mathrm{g}$, and between 0.03 and $3 \mu \mathrm{g}(P<0.05)$.

Since exogenous estrogen up-regulates SP mRNA expression and both ER-G and -13 are expressed in neurons of these ganglia $[62,82]$, we examined whether the estrogen effects on SP mRNA synthesis were ER-mediated. Administration of the ER antagonist ICI 182780 to ovariectomized rats $12 \mathrm{~h}$ prior to 1713-estradiol, reduces the effects of estrogen (at $3.0 \mu \mathrm{g}$ ) on SP mRNA expression (Fig. 4C). The partial blockage of SP mRNA synthesis by ER blocker ICI 182780 was statistically 


\section{A). SP mRNA in DRG during pregnancy}

i)

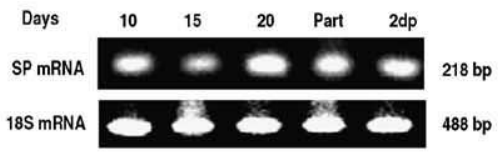

ii)

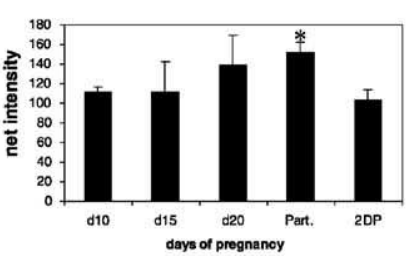

B). SP mRNA expression in DRG following estrogen treatment

i)

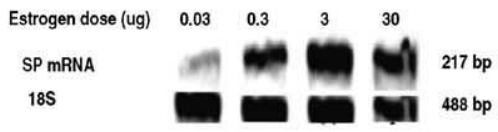

C). SP mRNA expression in DRG following ICI 182780 (ER blocker) and estrogen treatment

i)

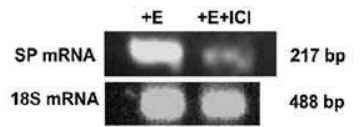

\section{D). ER- $\alpha$ mRNA expression in DRG during pregnancy}

i)

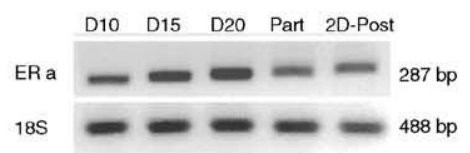

\section{E). ER- $\beta$ mRNA expression in DRG during pregnancy}

i)

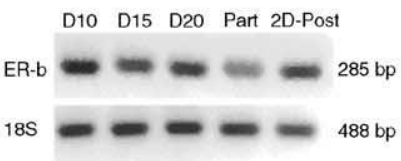

ii)

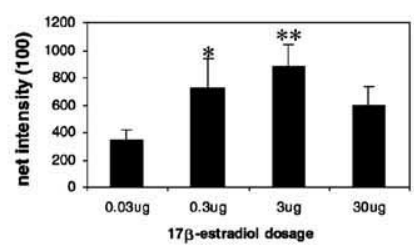

ii)

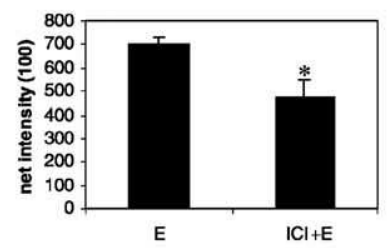

ii)

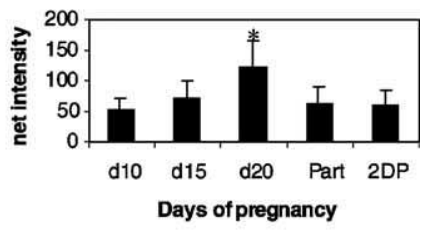

ii)

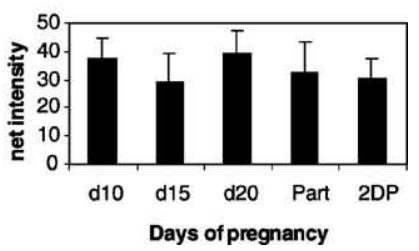

Fig. 4. Data from RT-PCR analysis showing changes in SP, ER-G and ER-13 mRNAs in L6-S1 DRG at representative time points during pregnancy, the effect of estrogen treatment, and the effect of an estrogen receptor blocker. SP (A), ER-G (D) and ER-13 (E) mRNAs in the DRG of rats at pregnant days 10 , 15, 20, parturient (Day 22) and 2-days postpartum. (B) Effect of short-term estrogen treatment, of various doses, on SP mRNA in DRG in ovariectomized rats. (C) Outcome of pretreatment with the estrogen receptor blocker (ICI 182 780) on the short-term treatment effects of estrogen on SP mRNA in DRG of ovariectomized rats. 18S mRNA was used as an internal control. Scanned images of SYB green-stained gels on the left (i) and intensity plotted as a histogram on the right (ii). (A) SP mRNA shows a trend toward up-regulation during pregnancy and decreasing after birth, (B) estrogen administration to ovariectomized rats up-regulates SP mRNA in a dose-related manner with a maximum effect at $3.0 \mu \mathrm{g}$, (C) prior administration of ER blocker ICI 182 780 partially prevented the estrogen-induced up-regulation of SP mRNA, (D) ER-G mRNA was up-regulated over pregnancy and decreased after birth, whereas ER-13 mRNA levels (E) remained relatively stable. Note the scale differences for the histograms for ER-G vs. ER-13 mRNA. E: estrogen treatment, ICI + E: estrogen blocker ICI $182780+$ estrogen treatment. (A) $* P<0.05$, compared to Day 10 ; (B) $* * P<0.001, * P<0.05$, compared to $0.03 \mu \mathrm{g}$ estrogen dosage; (C) $* P<0.01$, compared to estrogen treatment; (D) $* P<0.023$, compared to Day 10; (E) all days not statistically different; ( $t$-test). 
significant compared to the 1713-estradiol-treated animals $(P<0.05)$.

Because ICI 182780 blocks both subtypes of ER, namely ER-G and -13 , we examined whether the expression of both subtypes are in L6-S1 DRG for a clue as to the subtype likely to mediate SP mRNA expression in pregnancy. RT-PCR data revealed that ER-G mRNA tended to increase over pregnancy with a peak at Day 20 of pregnancy (Fig. 4D). In contrast, ER-13 mRNA levels generally remained stable across pregnancy and were basically unchanged from those expressed in the nonpregnant rat (Fig. 4E). The difference between Day 20 and Day 10 was statistically significant for ER-G mRNA $(P<0.023)$, whereas no significant difference was seen between any representative time points in the case of ER-13 mRNA.

\section{Discussion}

The important findings of this study are that (1) concentration of SP in L6-S1 DRG rises over the last trimester of pregnancy, but is lower in the cervix during the same period, (2) DRG neurons coexpress ER and SP, (3) SP mRNA in DRG increases over pregnancy and responds in a dose-related manner to estrogen, and (4) ER blocker ICI 182780 attenuates this estrogen effect. These data suggest that estrogen has a role in up-regulation of SP mRNA and SP synthesis, in part via the ER signaling pathway. These findings are novel in that they strongly implicate interactions between estrogen and the neuropeptide SP in the somata of DRG neurons, their central processes in the spinal cord and peripheral terminals in the uterine cervix.

Moreover, the fundamental components of neurogenic inflammation important for cervical ripening in the cervix of late-pregnant rats, i.e. a network of nerves immunoreactive for inflammation-associated neuropeptides and presence of their receptors closely associated with cervical venules during pregnancy, was established by a previous study [16]. The present findings support the data suggesting that SP is important in changes occurring at cervical ripening and parturition.

Various substances have been studied extensively for their involvement in parturition including cytokines (IL-1, -6, -8 and TNF), oxytocin, prostaglandins and steroid hormones $[1,51,83]$. Interestingly, disruption of individual genes for these substances fails to stop reproductive processes in mice [34] suggesting there is a multiplicity of factors at play in cervical ripening and parturition and possibly some, as yet, undiscovered factors. Along this line, Carlson and De Feo [11], Higuchi et al. [27] and Burden et al. [10] reported that severing the pelvic nerves enroute to the cervix interferes with, or blocks parturition. This prompted research on factors in the pelvic nerves that are crucial to cervical ripening and parturition.

The cervix is innervated largely by pelvic nerves $[4,5,58,65,66,85]$ arising from L6-S1 spinal cord segments, though there are contributions from the vagus $[15,30,36,56]$ and hypogastric nerves $[5,17,66]$. Sensory fibers of the pelvic nerve are most vital for parturition as bilateral dorsal rhizotomy at Days $8-10$ of pregnancy produces dystocia whereas bilateral transection of ventral roots does not [10]. Moreover, transection of pelvic and hypogastric nerves blocks reflexive postpartum ovulation that is stimulated by passage of the fetuses through the cervix [17]. The DRG is the major, if not exclusive, source of SP in the cervix $[57,58,85]$ and SP is present in small capsaicin-sensitive sensory neurons $[69,85]$. Afferent nerves that release transmitters from their central terminals in the spinal cord also perform an efferent function by releasing neuropeptides from their terminals in target tissue [29,48,52]. SP, when released from the sensory nerves, produces several effects in peripheral organs $[29,31,48]$ including vasodilation, increased permeability of postcapillary venules with plasma extravasation, and recruitment and activation of inflammatory immune cells. These effects are essential features of neurogenic inflammation and are involved in tissue rearrangements $[7,21,31,52,73,81]$. Tissue rearrangements of cervical ripening in preparation for parturition begin at about Day 20 in the rat $[16,18]$ and resemble those described for neurogenic inflammation [16]. Thus, our data showing increased synthesis of SP in the DRG over pregnancy, with a peak at about Day 20, taken in conjunction with decreasing levels in the cervix, possibly indicating increased release and utilization, support the hypothesis that SP and a local neurogenic inflammatory-type reaction are important components of cervical ripening [16,42]. It could be argued that increased SP in the DRG with decreased SP in the cervix may result from increased storage versus release. However, the fact that the SP receptor NK1, which is important in pain and inflammatory conditions [68], is up-regulated in the pregnant cervix maximally at Days 20-22 [16] is more consistent with the postulated increased release of SP in the cervix at this time, than increased storage. This data parallels that of estrogen effects on SP-receptor mRNA levels and SP binding in an in vivo and model cell system $[9,22,89]$. Moreover, the slight rise in SP concentration in the cervix of parturient animals may result from the maximized egress of immune cells from the vasculature at this stage, many of which synthesize SP [38].

In situ hybridization data revealed most intense 13-PPT signal in small neurons with light to moderate signal in medium-size neurons. This may explain why selective antidromic stimulation of C-type axons of (from small DRG neurons) and A-delta (from medium-size neurons) (which induce local neuropeptide release, including SP) have differential effects on pelvic organs. Stimulation of C-fibers (with a higher SP content) causes both vasodilation and neurogenic inflammation, whereas, stimulation at frequencies for A-delta fibers causes only vasodilation [66]. We infer that, based on the collective data above, cervical ripening involves a neurogenic inflammatory-type reaction as an orderly and timely component of cervix remodeling which is vital for 
passage of the fetus at parturition. In addition, increased SP synthesis in the DRG and transport to, and release in, the cervix at late pregnancy is an important part of this process in the rat. Though SP concentration is lower in the cervix over the last trimester of pregnancy, there was increased concentration of SP in the DRG and dorsal one-half of the spinal cord. The increased concentration of SP in the spinal cord is intriguing, but if it reflects peptide synthesized and transported from the DRG neurons, peptide intrinsic to the spinal cord, SP derived from supraspinal sources or a combination of these is presently unknown. Dorsal rhizotomy and capsaicin-treatment, showed that significant SP content of the L6 spinal dorsal horn is from CNS source(s), though the intrinsic sources were not identified [86].

Estrogen and progesterone play key roles in establishing the environment leading to successful pregnancy and full-term labor $[8,14,78,87]$. During the period of progesterone dominance in early pregnancy the cervix is firm and tightly closed. At late pregnancy a sharp rise in estrogen levels changes the estrogen: progesterone balance which favors cervical ripening [78]. This change in hormonal milieu up-regulates factors that enhance uterine contraction and cervical ripening, e.g. oxytocin receptor $[25,26,39,88]$ and immune cells [16,47]. Moreover, coexistence of ER and SP in sensory neurons of lumbosacral DRG neurons implicates estrogen in the regulation of SP expression and SP involvement in cervical ripening. Furthermore, the temporal coincidence in the rat (at about Day 20) in the rise of serum estrogen (and decline of progesterone) [8,46,76], up-regulation of ER-G mRNA, SP mRNA, and SP in L6-S1 DRG (present study), strongly supports the notion that estrogen, working through ERs, positively influences SP expression.

L6-S1 DRG neurons project axons to pelvic organs other than the uterus and cervix, e.g. the urinary bladder $[19,20,33,80]$ and some of these neurons express ERs [3]. Thus, estrogen could influence the function of the urinary system in addition to the reproductive tract $[2,6,32,84]$. This influence could occur at the level of the epithelium, smooth muscle, or nerves $[3,23,50]$. Consequently, it is likely that all ER-positive neurons examined in the present study were not necessarily uterus-related. Though, it should be noted that previous studies have not reported a direct effect of steroid hormones on bladder responses to nerve stimulation [74] and micturition thresholds were not altered by estrous cycle stage (i.e. circulating hormone level) in normal rats (but only in bladder inflamed rats) [32]. In any case, this information calls forth an important point, i.e. caution should be exercised when making interpretations about neurons expressing ERs and their role(s) only in reproductive organ circuitries.

Estrogen effects are mediated largely by ER-G and -13 $[35,37]$. Small- and medium-size sensory neurons in L6-S1 DRG express one or both ER isoforms [3,62,64]. The present study revealed that ER-G mRNA is up-regulated during pregnancy, whereas, ER-13 remains largely unchanged implying that ER-G may play a dominant role during preg- nancy and, possibly mediate up-regulation of SP synthesis. 1713-Estradiol stimulated SP mRNA synthesis in ovariectomized rats, an effect blocked by pretreatment with an ER antagonist suggesting that SP synthesis in the DRG during pregnancy may be regulated by the estrogen-ER signaling pathway. Because we do not know if the 13-PPT gene has an estrogen-responsive element (ERE) [54], it is not clear precisely how estrogen regulates SP. A proposal is that estrogen regulates SP synthesis indirectly by modulating NGF or trkA [43,77], which express EREs, and these regulate SP [43-45]. ICI 182780 , may, therefore, block SP up-regulation by preventing binding of the estrogen-ER complex to the ERE of NGF.

Taking the present data in concert with the current literature we propose one avenue by which estrogen may influence initiation of cervical ripening. Estrogen could enhance the sensitivity of nerves at the internal of the cervix to fetal mechanical stimuli and up-regulate synthesis of SP and NK1 in DRG and cervix, respectively with concomitant enhanced release of SP in the cervix. SP, in concert with other inflammation-associated neuropeptides, promotes a neurogenic inflammatory-type response and tissue rearrangements. Thus, SP, in part, under the influence of estrogen-ER-G, may help establish conditions critical for cervical ripening in preparation for parturition.

\section{Acknowledgments}

This work was supported in part by NIH grants NS22526 and NS33081 (RP) and FWF P-13512-Med (RA). We thank Jen Hafemeister for her excellent technical assistance.

\section{References}

[1] Arntzen KJ, Kjollesdal AM, Halgunset J, Vatten L, Austgulen R. TNF, IL-1, IL-6, IL-8 and soluble TNF receptors in relation to chorioamnionitis and preterm labor. J Perinatal Med 1998;26:17-26.

[2] Beach FA. Effects of gonadal hormones on urinary behavior in dogs. Physiol Behav 1974;12:1005-13.

[3] Bennet HL, Gustafsson JA, Keast JR. Estrogen receptor expression in lumbosacral dorsal root ganglion cells innervating the female rat urinary bladder. Autonom Neurosci 2003;105:90-100.

[4] Berkley KJ, Robbins A, Sato Y. Afferent fibers supplying the uterus in the rat. J Neurophysiol 1988;59:142-63.

[5] Berkley KJ, Robbins A, Sato Y. Functional differences between afferent fibers in the hypogastric and pelvic nerves innervating female reproductive organs in the rat. J Neurophysiol 1993;69:533-44.

[6] Blakeman P, Hilton P, Bulmer J. Oestrogen and progesterone receptor expression in the female lower urinary tract, with reference to oestrogen status. Br J Urol 2000;86:32-8.

[7] Brain S. Sensory neuropeptides in the skin. In: Geppetti P, Holzer P, editors. Neurogenic inflammation. Boca Raton, FL: CRC Press; 1996. p. 229-44.

[8] Bridges RS. A quantitative analysis of the roles of dosage, sequence and duration of estradiol and progesterone exposure in the regulation of maternal behaviour in the rat. Endocrinology 1984;114:930-40.

[9] Brown ER, Harlan RE, Krause JE. Gonadal steroid regulation of substance P (SP) and SP-encoding messenger ribonucleic acids 
in the rat anterior pituitary and hypothalamus. Endocrinology 1990;126:330-40.

[10] Burden HW, Price GT, Renegar RH, Hodson CA. Effects of peripheral nerve lesions during pregnancy on parturition in rats. Anat Embryol (Berl) 1990;182:499-501.

[11] Carlson RR, De Feo VJ. Role of the pelvic nerve vs. the abdominal sympathetic nerves in the reproductive function of the female rat. Endocrinology 1965;77:1014-22.

[12] Carter MS, Krause JE. Structure, expression and some regulatory mechanisms of the rat preprotachykinin gene encoding substance $\mathrm{P}$, neurokinin A, neuropeptide $\mathrm{K}$ and neuropeptide gamma. J Neurosci 1990;10:2203-14.

[13] Challis JRG. Mechanism of parturition and preterm labor. Obstet Gynecol Surv 2000;55:650-60.

[14] Chaim W, Mazor M. The relationship between hormones and human parturition. Arch Gyne Obstet 1998;262:43-51.

[15] Collins JJ, Lin CE, Berthoud HR, Papka RE. Vagal afferents from the uterus and cervix provide direct connections to the brainstem. Cell Tissue Res 1999;295:43-54.

[16] Collins JJ, Usip S, McCarson KE, Papka RE. Sensory nerves and neuropeptides in uterine cervical ripening. Peptides 2002;23:167-83.

[17] Cunningham ST, Rosenblatt JS, Komisaruk BR. Reflexive ovulation in the rat, induced by caesarean section, is blocked by pelvic and/or hypogastric nerve transection. Neuroendocrinology 1992;56:393-6.

[18] Cunningham F, MacDonald P, Gent N, LaVeno K, Gilstrap L. Normal labor and delivery and the puerperium. Parturition: biomolecular and physiologic processes. In: Williams obstetrics. Norwalk, CT: Appleton and Lange Publishers; 1993. p. 297-361.

[19] de Groat WC, Kruse MN. Central processing and morphological plasticity in lumbosacral afferent pathways from the lower urinary tract. In: Mayer EA, Raybould HE, editors. Basic and clinical aspects of chronic abdominal pain. Pain research and clinical management. Amsterdam: Elsevier; 19932. p. 219-35.

[20] Donovan MK, Winternitz SR, Wyss JM. An analysis of the sensory innervation of the urinary system of the rat. Brain Res Bull 1983;11:321-4.

[21] Dray A. Neurogenic mechanisms and neuropeptides in chronic pain. Prog Brain Res 1996;110:85-94.

[22] Duval P, Lenoir V, Kerdelhue B. Ovarian steroid modulation of neurokinin contents in hypothalamus, pituitary, trigeminal nucleus, and cervical spinal cord of the ovariectomized female rat. J Neuroendocrinol 1998;10:823-8.

[23] Eika B, Salling LN, Christensen LL, Anderson A, Laurberg S, Danielsen CC. Long-term observation of the detrusor smooth muscle in rats: its relationship to ovariectomy and estrogen treatment. Urol Res 1990;18:439-42.

[24] Friend KE, Resnick EM, Ang LW, Shupnik MA. Specific modulation of estrogen receptor mRNA isoforms in rat pituitary throughout estrous cycle and in response to steroid hormones. Mol Cell Endocrinol 1997;131:147-55.

[25] Fuchs AR, Periyasamy S, Alexandrova M, Soloff MS. Correlation between oxytocin receptor concentration and responsiveness to oxytocin in pregnant rat myometrium: effects of ovarian steroids. Endocrinology 1983;113:742-9.

[26] Hendrix EM, Myatt L, Sellers S, Russell PT, Larsen WJ. Steroid hormone regulation of rat myometrium gap junction formation: effects on cx43 levels and trafficking. Biol Reprod 1995;52:547-60.

[27] Higuchi T, Uchide K, Honda K, Negoro H. Pelvic neuroctomy abolishes the fetus-expulsion reflex and induces dystocia in the rat. Exp Neurol 1987;96:443-55.

[28] Hökfelt T, Kellerth JO, Nilsson G, Pernow B. Substance P: localization in the central nervous system and in some primary sensory neurons. Science 1975;190:889-90.

[29] Holzer P. Local effector functions of capsaicin-sensitive sensory nerve endings: involvement of tachykinins calcitonin gene-related peptide and other neuropeptides. Neuroscience 1988;24:739-68.
[30] Hubscher CH, Berkley KJ. Spinal cord and vagal influences on the responses of rat solitary nucleus neurons to stimulation of the uterus, cervix and vagina. Brain Res 1995;702:251-4.

[31] Jancso N, Jancso-Gabor A, Szolcsanyi J. Direct evidence for neurogenic inflammation and its prevention by denervation and by pretreatment with capsaicin. Br J Pharmacol 1967;31:138-51.

[32] Johnson OL, Berkley KJ. Estrous influences on micturition thresholds of the female rat before and after bladder inflammation. Am J Physiol 2002;282:R289-94.

[33] Keast JR, de Groat WC. Segmental distribution and peptide content of primary afferent neurons innervating the urogenital organs and colon of male rats. J Comp Neurol 1992;319:615-23.

[34] Kimura T, Ogita K, Kusui C, Ohashi K, Azuma C, Murata Y. What knockout mice tell us about parturition. Rev Reprod 1999;4:73-80.

[35] Koike S, Sakai M, Muramatsu M. Molecular cloning and characterization of rat estrogen receptor cDNA. Nuclei Acids Res 1984;15:2499-513.

[36] Komisaruk BR, Bianca R, Sansone G, Gomez LE, Cueva-Rolon R, Beyer $\mathrm{C}$, et al. Brain-mediated response to vaginocervical stimulation in spinal cord-transected rats: role of the vagus nerves. Brain Res 1996;708:128-34.

[37] Kuiper GGJM, Enmark E, Pelto-Huikko M, Nilsson S, Gustafsson JA. Cloning of a novel estrogen receptor expressed in the rat prostate and ovary. Proc Natl Acad Sci USA 1996;93:5925-30.

[38] Lai JP, Douglas SD, Zhao M, Ho WZ. Quantification of substance $\mathrm{P}$ mRNA in human mononuclear phagocytes and lymphocytes using a mimic-based RT-PCR. J Immunol Methods 1999;230:149-57.

[39] Lau TM, Kerton DJ, Gow CB, Fairclough RJ. Increase in concentration of uterine oxytocin receptors and decrease in response to 13,14-dihydro-15-keto prostaglandin F2 alpha in ewes after withdrawal of exogenous progesterone. J Reprod Fertil 1992;95: 88593.

[40] Lembeck F, Bernatzky G, Gamse R, Saria A. Characterization of substance P-like immunoreactivity in submammalian species by high performance liquid chromatography. Peptides 1985;6(3):231-6.

[41] Leung MS, Wong CC. Expression of putative neurotransmitters and neuronal growth-related genes in Merkel cell-neurite complexes of the rats. Life Sci 2000;66:1481-90.

[42] Liggins GC. Cervical ripening as an inflammatory reaction. In: Ellwood DA, Anderson ABM, editors. The cervix in pregnancy and labor. Edinburgh: Churchill Livingstone; 1981. p. 1-9.

[43] Lindsay RM, Harmer AJ. Nerve growth factor regulates expression of neuropeptides genes in adult sensory neurons. Nature 1989;337: $362-4$.

[44] Liuzzi FJ, Scoville SA, Bufton SA. Long-term estrogen replacement coordinately decreases trkA and 13-PPT mRNA levels in dorsal root ganglion neurons. Exp Neurol 1999;155:260-7.

[45] Liuzzi FJ, Scoville SA, Bufton SA. Effects of short-term estrogen replacement coordinately decrease trkA mRNA levels in axotomized dorsal root ganglion neurons. Exp Neurol 1999;159:433-40.

[46] Lye SJ, Nicholson BJ, Mascarenhas M, MacKenzie L, Petrocelli T. Increased expression of connexin-43 in the rat myometrium during labor is associated with an increase in the plasma estrogen progesterone ratio. Endocrinology 1993;132:2380-6.

[47] Mackler AM, Iezza G, Akin MR, McMillan P, Yellon SM Macrophage trafficking in the uterus and cervix precedes parturition in the mouse. Bio Reprod 1999;61:87-883.

[48] Maggi CA, Meli A. The sensory-efferent function of capsaicinsensitive sensory neurons. Gen Pharmacol 1988;19:1-43.

[49] Maggi CA. The dual nature of the tachykinin NK1 receptor. Trends Pharmacol Sci 1997;18:351-5.

[50] Makela S, Strauss L, Kuiper G, Valve G, Salmi S, Santti R, et al. Differential expression of estrogen receptors alpha and beta in adul rat accessory sex glands and lower urinary tract. Mol Cell Endocrinol 2000;164:109-16.

[51] Matsuzaki N, Taniguchi T, Shimoya K, Neki R, Okada T, Saji F, et al. Placenta interleukin- 6 production is enhanced in intrauterine infection but not in labor. Am J Obstet Gynecol 1993;168:94-7. 
[52] McDonald DM, Bowden JJ, Baluk P, Bunnett NW. Neurogenic inflammation. A model for studying efferent actions of sensory nerves. Adv Exp Med Biol 1996;410:453-62.

[53] Nawa H, Kotani H, Nakanishi S. Tissue-specific generation of two preprotachykinin mRNAs from gene by alternative RNA splicing. Nature 1984;312:729-34.

[54] Nilsson S, Gustafsson JA. Estrogen receptor transcription and transactivation: basic aspects of estrogen action. Breast Cancer Res 2000;2:360-6.

[55] Olgart L, Hökfelt T, Nilsson G, Pernow B. Localization of SP-like immunoreactivity in nerves in the tooth pulp. Pain 1977;4:153-9.

[56] Ortega-Villalobos M, Garcia-Bazan M, Solano-Flores LP, Ninomiva-Alarcon JG, Guevara-Guzman R, Wayner MJ. Vagus nerve afferent and efferent innervation of the rat uterus: an electrophysiological and HRP study. Brain Res Bull 1990;25:365-71.

[57] Papka RE, Cotton JP, Traurig HH. Comparative distribution of neuropeptide tyrosine-, vasoactive intestinal polypeptide-, substance P-immunoreactive, acetylcholinestersase-positive and noradrenergic nerves in the reproductive tract of the female rat. Cell Tissue Res 1985;242:475-90.

[58] Papka RE. Some nerve endings in the female rat pelvic paracervical autonomic ganglia and varicosities in the uterus contain calcium generelated peptide and originate from the dorsal root ganglia Neuroscience 1990;39:459-70.

[59] Papka RE, McNeill DL, Thompson D, Schmidt HHW. Nitric oxide nerves in the uterus are parasympathetic, sensory and contain neuropeptides. Cell Tissue Res 1995;279:339-49.

[60] Papka RE, Storey-Workley M, Collins J, Usip S. Sensory and parasympathetic neurons projecting axons to the uterus synthesize estrogen receptors (ER-G and ER-13) and possess attributes fundamental for cervical ripening. Soc Neurosci Abstr 2000;26:1679.

[61] Papka RE, Collins JJ, McCarson KE. Neuropeptides, neurogenic inflammation and ripening of the uterine cervix. In: Proceedigns of the Neuropeptides 2001 Symposium and Meetings, Jerusalem, Israel. J Mol Neurosci 2001;16:80.

[62] Papka RE, Storey-Workley M. Estrogen receptor-alpha and -beta coexist in a subpopulation of sensory neurons of female rat dorsal root ganglia. Neurosci Lett 2002;319:71-4.

[63] Papka RE, Srinivasan K, Miller E, Hayashi S. Localization of estrogen receptor protein and estrogen receptor mRNA in peripheral autonomic and sensory neurons. Neuroscience 1997;79: 1153-63.

[64] Papka RE, Storey-Workley M, Shughrue PJ, Merchenthaler I, Collins JJ, Usip S, et al. Estrogen receptor-G and -13-immunoreactivity and mRNA in neurons of sensory and autonomic ganglia and spinal cord. Cell Tissue Res 2001;304:193-214.

[65] Papka RE, Traurig HH. Autonomic and visceral sensory innervation of the female reproductive system: special reference to neurochemical markers in nerves and ganglionic connections. In: Maggi CA, editor. The autonomic nervous system (Burnstock G, series editor); Vol. VI: Nervous control of the urogenital system. London: Harwood Academic Publishers; 1993. p. 421-64.

[66] Peters LC, Kristal MB, Komisaruk BR. Sensory innervation of the external and internal genitalia of the female rat. Brain Res 1987;408:199-204.

[67] Pinter E, Szolcsanyi J. Plasma extravasation in the skin and the pelvic organs evoked by antidromic stimulation of the lumbosacral dorsal roots of the rat. Neuroscience 1995;68:603-14.

[68] Quartara L, Maggi CA. The tachykinin NK1 receptor. Part II: Distribution and pathophysiological roles. Neuropeptides 1998;32:149.

[69] Rambourg A, Clermont Y, Beaudet A. Ultrastructural features of six types of neurons in rat dorsal root ganglia. J Neurocytol 1983;12:4264.
[70] Regoli D, Nguyen OT, Jukic D. Neurokinin receptor subtypes characterized by biological assays. Life Sci 1994;54:2035-47.

[71] Ribeiro-da-Silva A, Hökfelt T. Neuroanatomical localization of substance $\mathrm{P}$ in the central nervous system and sensory neurons. Neuropeptides 2000;34:256-71.

[72] Roch-Arveiller M, Regoli D, Chanaud B, Lenoir M, Muntaner O, Stralzko S, et al. Tachykinins: effects on motility and metabolism of rat polymorphonuclear leukocytes. Pharmacology 1986;33:266-73.

[73] Saria A, Gamse R, Petermann J, Fischer JA, Theodorsson-Norheim E, Lundberg JM. Simultaneous release of several tachykinins and calcitonin gene-related peptide from rat spinal cord slices. Neurosci Lett 1986;63:310-4.

[74] Sato S, Hayashi RH, Garfield RE. Mechanical responses of the rat uterus, cervix, and bladder to sitmulation of hypogastric and pelvic nerves in vivo. Biol Reprod 1989;40:209-19.

[75] Saunders PT, Millar MR, Williams K, MacPherson S, Harkiss D, Anderson RA, et al. Differential expression of estrogen receptor-G and -13 and androgen receptor in the ovaries of marmosets and humans. Biol Reprod 2000;63:1098-10105.

[76] Shaikh AA. Estrone and estradiol levels in the ovarian venous blood from rats during the estrous cycle and pregnancy. Biol Reprod 1971;5:297-307.

[77] Sohrabji F, Miranda RC, Toran-Allerand CD. Estrogen differentially regulates estrogen and nerve growth factor receptor mRNAs in adult sensory neurons. J Neurosci 1994;14:459-71.

[78] Steer PJ. The endocrinology of parturition in the human. Baillieres Clin Endocrinol Metab 1990;4:333-49.

[79] Shew RL, Papka RE, McNeill DL. Substance P and calcitonin generelated peptide immunoreactivity in nerves of the rat uterus: localization, colocalization and effects on uterine contractility. Peptides 1991;12:593-600.

[80] Su HC, Polak JM, Mulderry PK, Ghatei MA, Gibson SJ, Terenghi $\mathrm{G}$, et al. Calcitonin gene-related peptide immunoreactivity in afferent neurons supplying the urinary tract: combined retrograde tracing and immunohistochemistry. Neuroscience 1986;18:727-47.

[81] Szolcsanyi J. Capsaicin-sensitive sensory nerve terminals with local and systemic efferent functions: facts and scopes of an unorthodox neuroregulatory mechanism. Prog Brain Res 1996;113:343-59.

[82] Taleghany N, Sarajari S, DonCarlos LL, Gollapudi L, Oblinger MM. Differential expression of estrogen receptor alpha and beta in the rat dorsal root ganglion neurons. J Neurosci Res 1999;57:603-15.

[83] Taniguchi T, Matsuzaki N, Kameda T, Shimoya K, Jo T, Saji F, et al. The enhanced production of placental interleukin-1 during labor and intrauterine infection. Am J Obstet Gynecol 1991;165:131-7.

[84] Tansy MF, Kaufman R. Influence of sex hormones on frequency of micturition. Nature 1966;211:1184-5.

[85] Traurig HH, Papka RE, Rush ME. Effects of capsaicin on reproductive function in the female rat: role of peptide-containing primary afferent nerves innervating the uterine cervix in the neuroendocrine copulation response. Cell Tissue Res 1988;253:573- 81 .

[86] Tuchscherer MM, Knox C, Seybold VS. Substance P and cholecystokinin-like immunoreactive varicosities in somatosensory and autonomic regions of the rat spinal cord: a quantitative study of coexistence. J Neurosci 1987;7:3984-95.

[87] Tulchinsky D, Hobel CJ, Yeager E, Marshall JR. Plasma estrone, estradiol, estriol, progesterone, and 17-hydroxyprogesterone in human pregnancy. I. Normal pregnancy. Am J Obstet Gynecol 1972;112:1095-100.

[88] Vallet JL, Lamming GC, Battern M. Control of endometrial oxytocin receptor and uterine response to oxytocin by progesterone and oestradiol in the ewe. J Reprod Fertil 1990;90:625-34.

[89] Villablanca AC, Hanley MR. 1713-Estradiol stimulates SP receptor gene expression. Mol Cell Endocrinol 1997;135:109-17. 